Vol 31, No. 116, Feb 2019: 28- 39.

\title{
Correlations of Organizational Justice and Professional Commitment with the Demographic Variables of Nurses
}

\author{
Fatemeh Rakhshany Zabol ${ }^{1}, *$ Omolbanin Akbari $^{2}$, Fatemeh Kiani ${ }^{3}$, Faezeh Sarhadi ${ }^{4}$
}

\begin{abstract}
Background \& Aims: Nurses are the primary agents in patient care, who are in direct contact with patients. In addition to persistence in the nursing profession and job satisfaction, professional commitment could enhance patient safety and quality of patient care. The present study aimed to assess the correlations between organizational justice and professional commitment with the demographic variables of nurses in the teaching hospitals affiliated to Zahedan University of Medical Sciences, Iran in 2018.

Materials \& Methods: This descriptive-correlation study was conducted on 298 nurses, who were selected via stratified sampling from the hospitals in Zahedan, Iran. Data were collected using Lin's nurses' professional commitment scale and Moorman and Niehoff's organizational justice questionnaires. Data analysis was performed in SPSS version 21 using one-way analysis of variance (ANOVA), independent t-test, and Pearson correlation-coefficient at the significance level of 0.05 .

Results: The mean scores of professional commitment and organizational justice were $3.68 \pm 0.55$ and $3.97 \pm$ 1.52, respectively. In addition, the results of Pearson's correlation-coefficient showed a positive, significant correlation between the variables of organizational justice and nurses professional $(\mathrm{P}<0.001 ; \mathrm{r}=0.23)$. The mean scores of nursing cognition $(\mathrm{P}=0.01)$ and persistence in the nursing professionals $(\mathrm{P}=0.03)$ were significantly higher in male nurses compared to the female nurses. Moreover, persistence in the nursing profession was significantly higher in married nurses compared to the single nurses $(\mathrm{P}=0.02)$. The mean score of total organizational justice and the dimensions of distributive justice and interactional justice were significantly higher in the male nurses compared to the female nurses $(\mathrm{P}<0.05)$. However, no significant correlation was observed between organizational justice and its dimensions with marital status $(\mathrm{P}>0.05)$.

Conclusion: Healthcare system managers could develop and implement interventions to increase the perceived organizational justice of nurses, especially in the terms of distributive justice, in order to improve the professional commitment of these healthcare professionals and improve the quality of nursing care.
\end{abstract}

Keywords: Professional Commitment, Organizational Justice, Nurses

\section{Conflict of Interest: No}

How to Cite: Rakhshany Zabol F, Akbari O, Kiani F, Sarhadi F. Correlations of Organizational Justice and Professional Commitment with the Demographic Variables of Nurses. Iran Journal of Nursing. 2019; 31(116):28-39.

Received: 13 Nov 2018

Accepted: 10 Feb 2019

\footnotetext{
1. MS in Health Education and Promotion, Social Determinants of Health Research Center, School of Health, Birjand University of Medical Sciences, Birjand, Iran

2. Lecturer, Department of Nursing, Zahedan Branch, Islamic Azad University, Zahedan, Iran (*Corresponding author) Tel: 09153780821 $\quad$ Email: o.akbari@iauzah.ac.ir

${ }^{3}$. Lecturer, Community Nursing Research Center, Zahedan University of Medical Sciences, Zahedan, Iran

4. BS Student in Nursing, School of Nursing, Zahedan Branch, Islamic Azad University, Zahedan, Iran
} 


\title{
همبستى عدالت سازمانى و تعهد حرفهاى و ارتباط آنها با متغير هاى جمعيتشناختى در يرستاران
}

فاطمه رخشانى زابل '، *ام البنين اكبرى '، فاطمه كيانى '، فائزه سرحدى

\begin{abstract}
جـكيuه

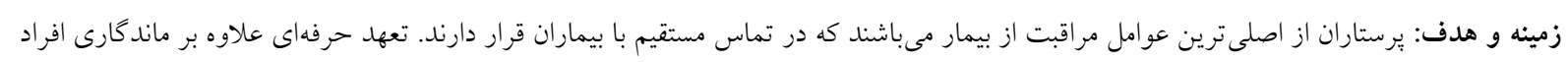

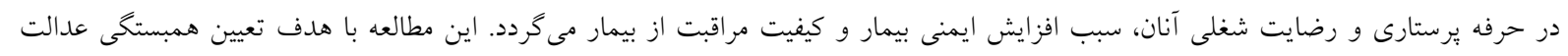

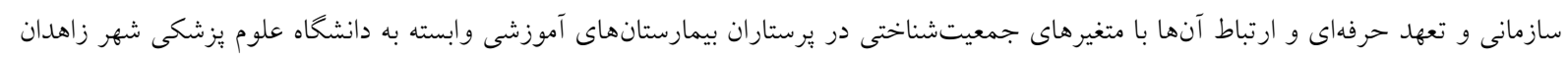

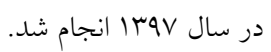
روش بررسى: در اين مطالعه توصيفى - همبستخى 191 بر برستار به روش نمونه كيرى طبقهاى از بيمارستانهاى شهر زاهدان انتخاب شدند. دادهها توسط

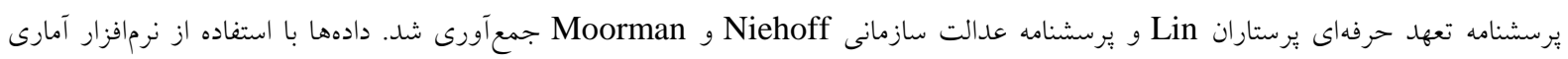

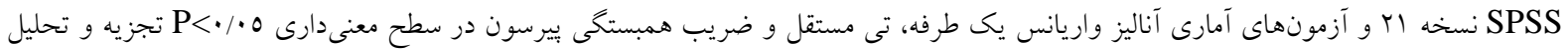
شدند.

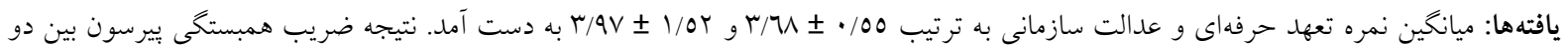

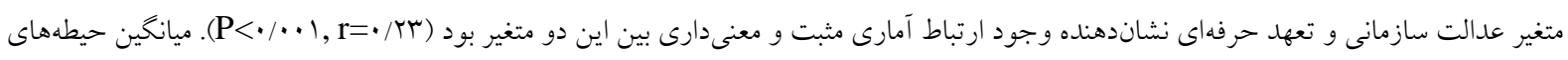

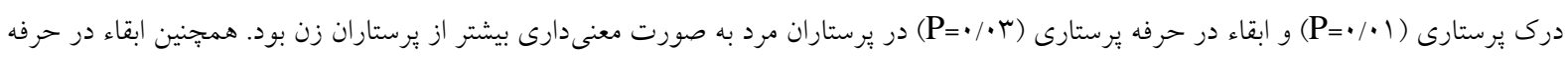

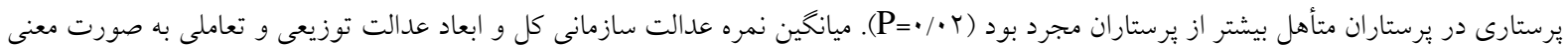

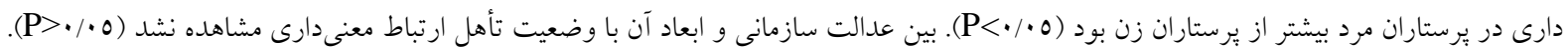

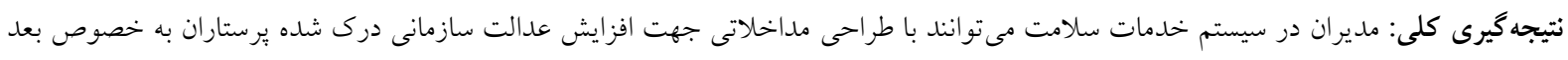

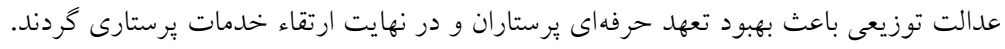

كليد وازهها: تعهد حرفهاى، عدالت سازمانى، برستاران تعارض منافع: ندارد تاريخ دريافت:

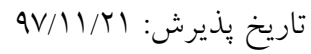

مقدمه

' ' كارشناس ارشد آموزش بهداشت و ارتقاء سلامت، مركز تحقيقات عوامل اجتماعى مؤثر بر سلامت، دانشكده بهداشت، دانشكًاه علوم يزشكى بيرجند، بيرجند، ايران.

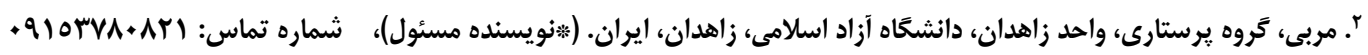
Email: o.akbari@iauzah.ac.ir

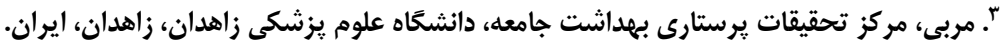

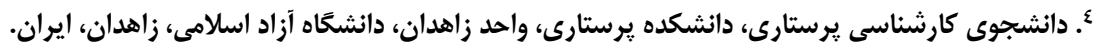


اثرات مثبت تعهد حرفهاى براى برستاران و سيستم

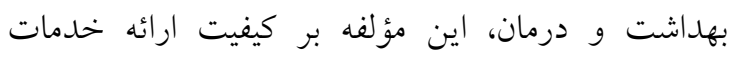

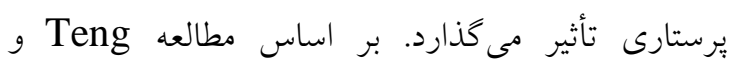

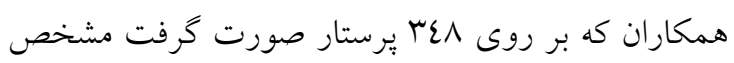

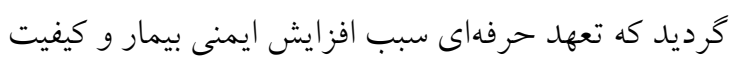
مراقبت از بيمار مىشود (َ). تعهد يكى از ييش شرطهاى ضرورى براى باقى ماندن در

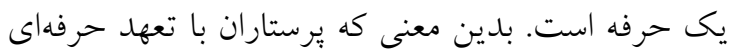

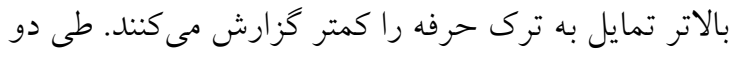

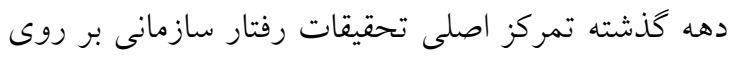

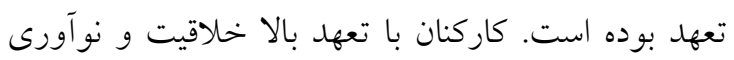
بيشترى داشته و سطح بالايى از اعتماد و قصد انجام كار

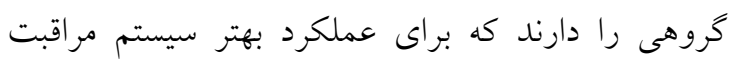

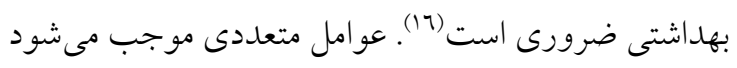

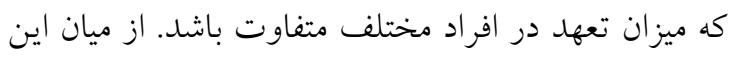

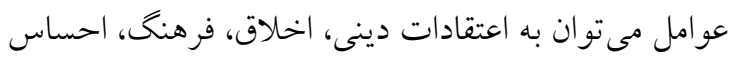

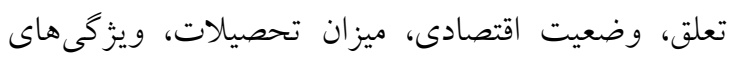

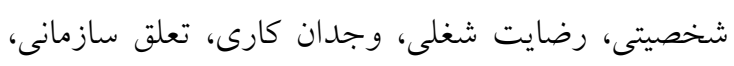
درآمد، محل خدمت، سابقه كار و عدالت سازمانى اشاره كرد يكى از عوامل تأثير كذار بر حفظ كاركنان احساس برخورد

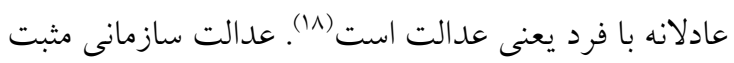

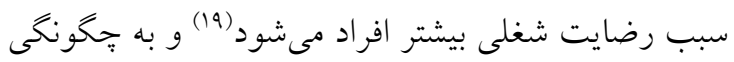

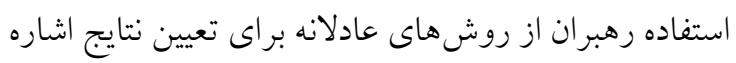

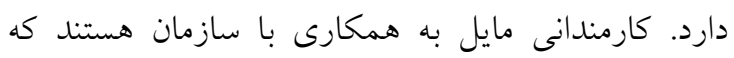
احساس كنند تلاشهايشان در سازمان به طور عادلانه باداش داده مىشود (1). عدالت سازمانى به درك افراد از عدالت در يكى سازمان

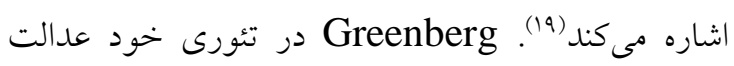
سازمانى را بهعنوان ديدكاه اعضاء سازمان درباره عدالت در توزيع منابع در دسترس تعريف مى كند. اين تئورى به عنوان

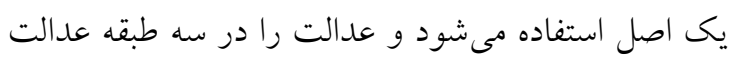
توزيعى، عدالت رويهاى و عدالت تعاملى، طبقهبندى مى آنى

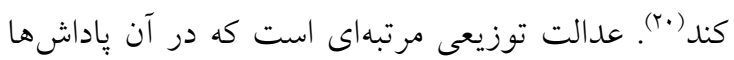

يرستارى يك حرفه بشردوستانه است و به دليل ساختار

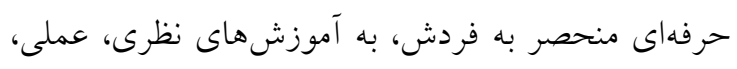

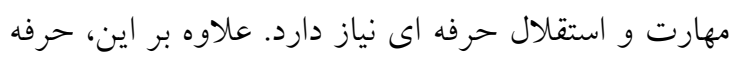

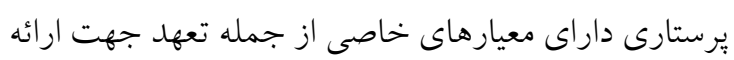

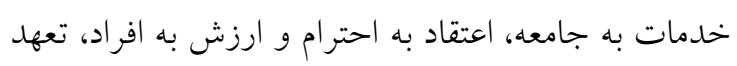
به آموزش و استقلال مى باشد كه تعهد مفهوم اصلى در ميان اين معيارهاست (1) تعهد مكانيزمى است كه سبب ايجاد رفتار سازگار در

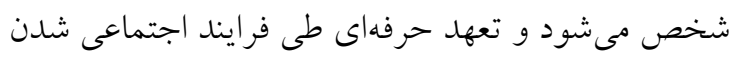

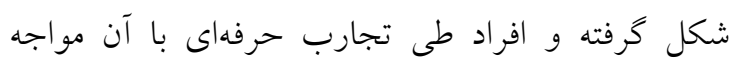

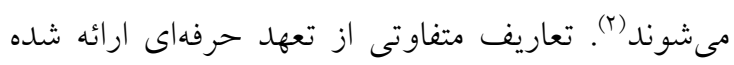

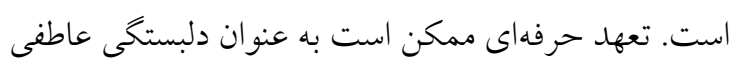
كاركنان به حرفه خود تعريف شود كه با احترام و اعتقاد

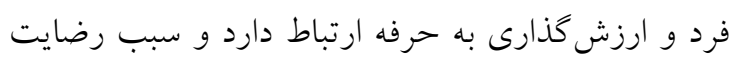

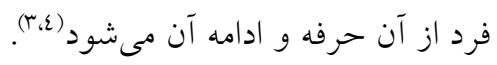

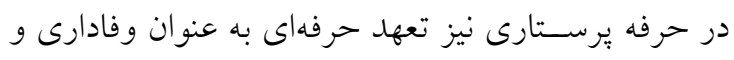

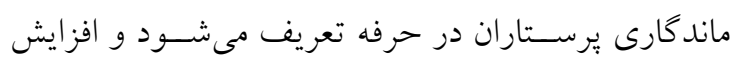

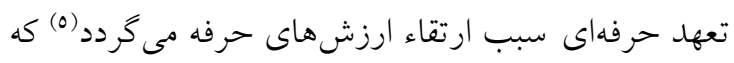

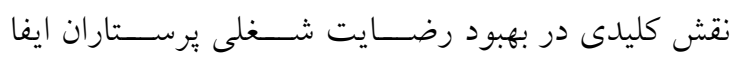

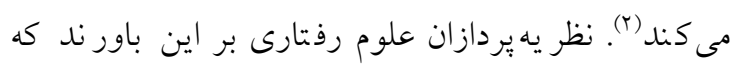

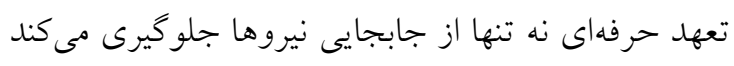

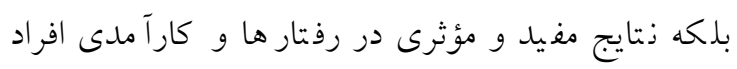

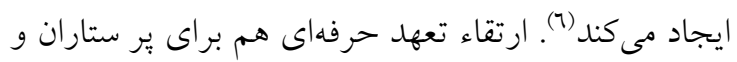

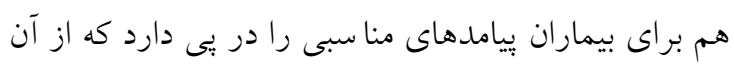

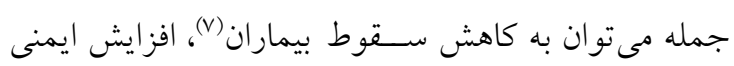

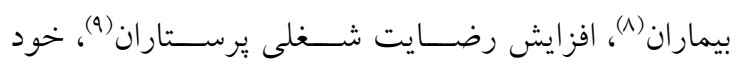

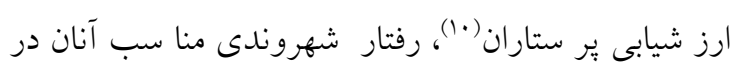

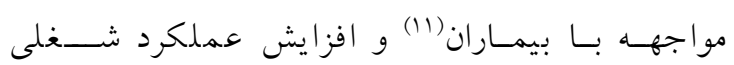
برستاران(rا، (1) اشاره كرد. Fontenla gould

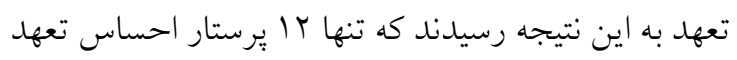

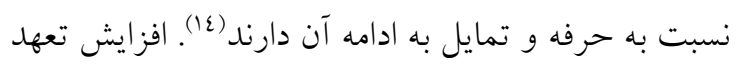
حرفهاى موجب مىشود كه افراد از حرفه شان رضايت

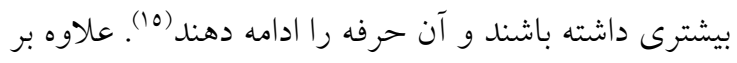


مشخص كردن ميز ان تعهل حرفه اى يرستاران و عوامل مؤثر

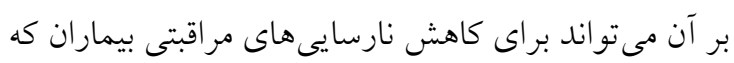

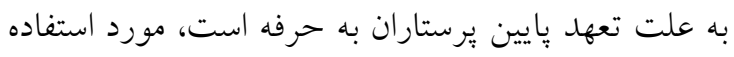

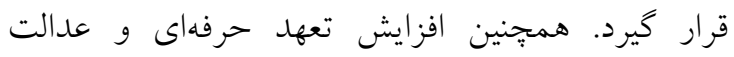

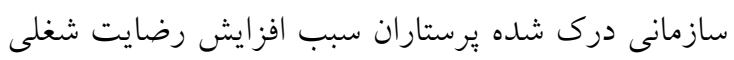

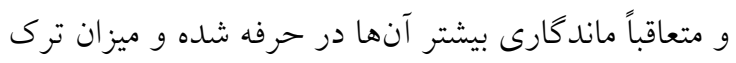

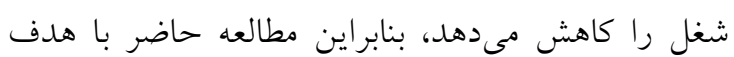
تعيين همبستكى عدالت سازمانى و تعهد حرفهاى و ارتباط

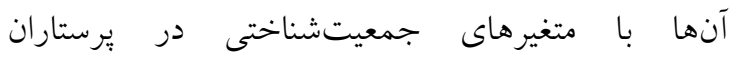
بيمارستانهاى آموزشى وابسته به دانشخاه علوم يزشكى إنى شهر زاهدان در سال لوبrا انجام شد.

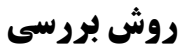

در اين مطالعه توصيفى - همبستخى جامعه يزوهش رورائ را تمام يرستاران شاغل در بيمارستانهاى آموزشى دانشخاه علوم

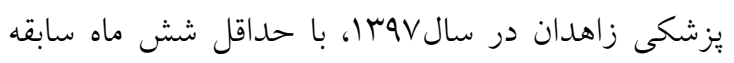
كار تشكيل دادند. اين مطالعه در كميته اخلاق دانشخاه

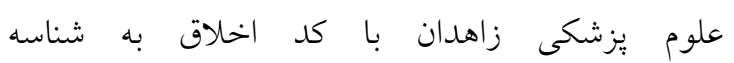
IR.ZAUMS.REC.1397.310 به تصويب رسيد. در مرحله اول يّ از مر اجعه به مديريت يرستارى دانشگاه

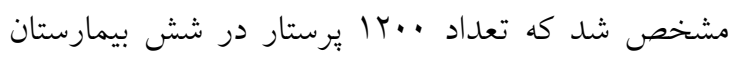

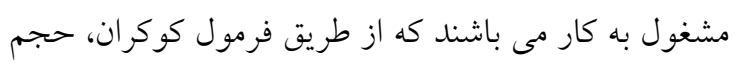

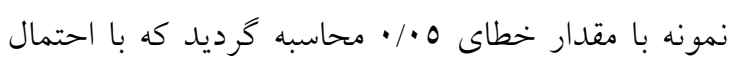

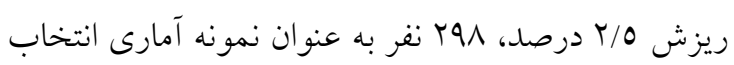

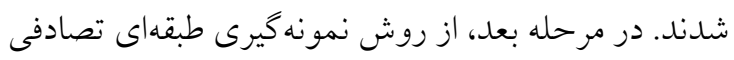
استفاده شد. بدين صورت كه سهم هر بيمارستان از نمونه

مشخص شد. كه در مرحله سوم يس از مراجعه به بيمارستان بر اساس

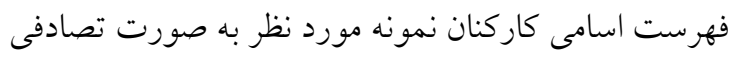

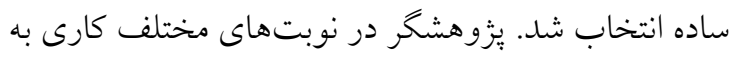

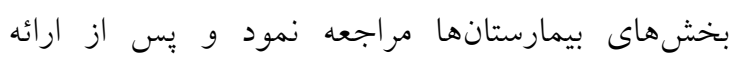

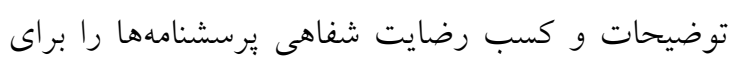

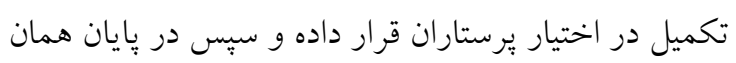

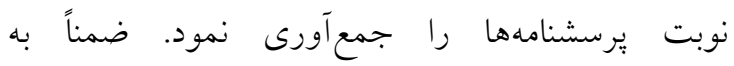

به صورتى منصفانه تخصيص داده مىشود. عدالت رويهاى يعنى آنهايى كه تحت تأثير تصميمات، تخصيص مزايا يا

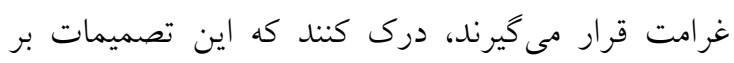
مبناى روشها و راهبردهاى منصفانه صورت گرقفته است.

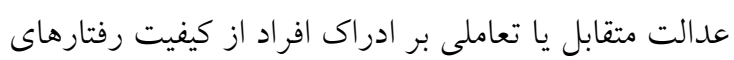

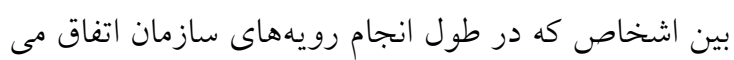

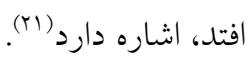
نتايج مطالعه حاتم و همكاران بر روى ل. .ع يرستار شاغل

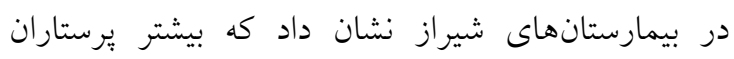
شركت كننده (77\%) از عدالت سازمانى درى شده بالائي برخوردار بودند و ميانخين نمره عدالت سازمانى درك شده

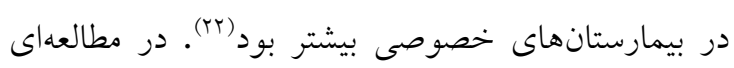

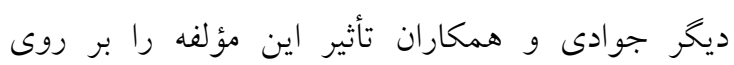

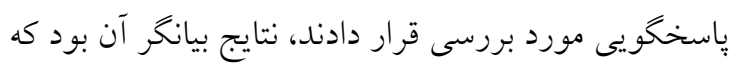
عدالت سازمانى در بيمارستانها در سطح متوسط قرار دارد.

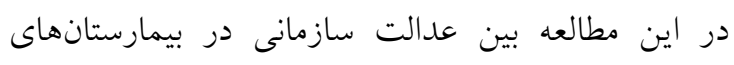

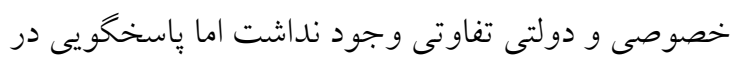

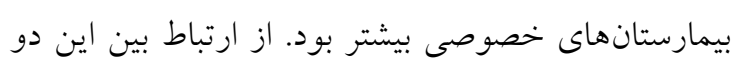

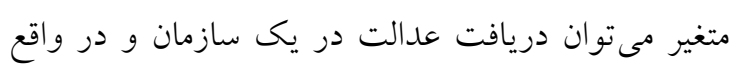

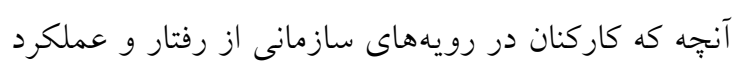

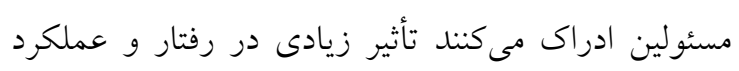

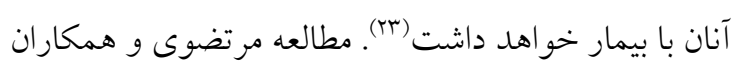
بر روى 191 يرستار مؤيد اين مطلب است كه عدالت رويه

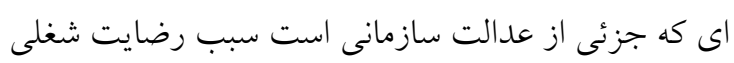

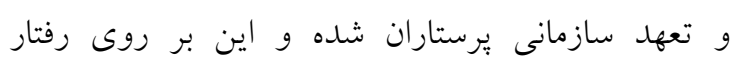
شهروندى مشترى مدار يرستاران تأثير مثبت مى كذارد (Yع).

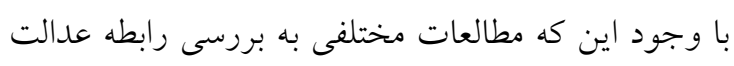

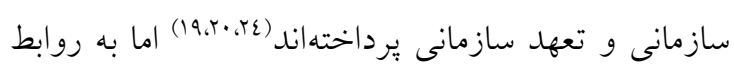

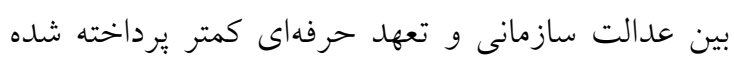

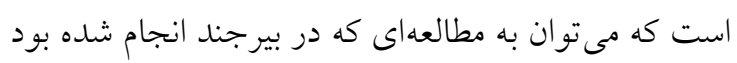

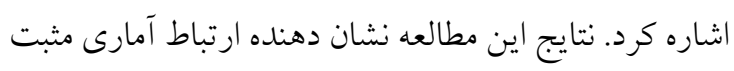
و معنى دارى بين اين دو متغير در ميان برستاران بيرجند 
مىباشد (TVV). نويسند كان مطالعه حاضر بايايى اين برسشنامه

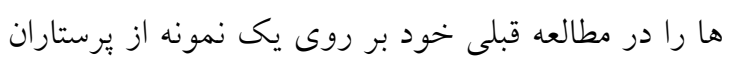

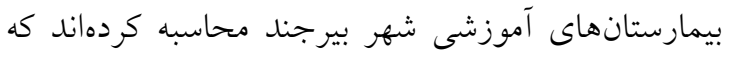

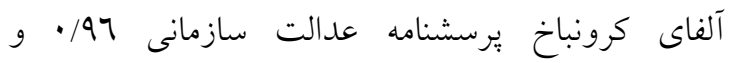

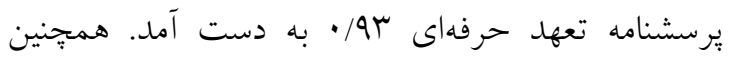
روايى صورى و محتوايى اين برسشنامه توسط ده نفر از اعضاى هيئت علمى دانشكده برستارى و مامايى دانشخاه علوم يزشكى بيرجند تأييد شد (ro).

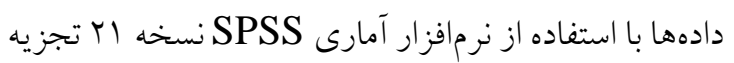
و تحليل شدند. پِ از ورود دادهها به نرمافزار ابتدا

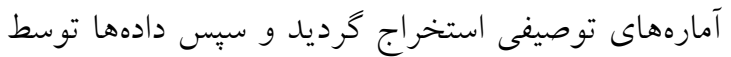
آزمونهاى آناليز واريانس يك طرفه، تى مستقل، آزمون

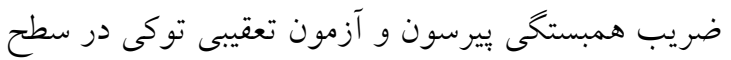
معنى دارى P>• P مورد تجزيه و تحليل قرار كرفت.

\section{يافتهها}

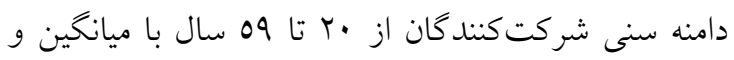

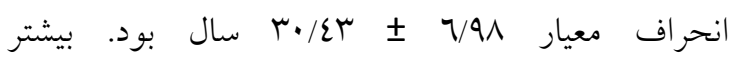

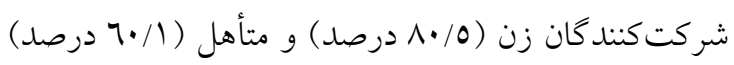

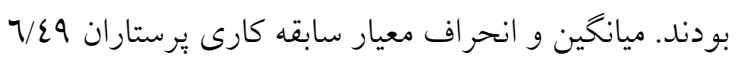

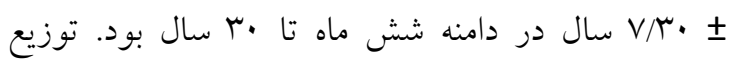
فراوانى اطلاعات جمعيت شناختى در جدول شماره ا ذكر

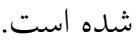
از ميان ابعاد تعهل حرفهاى بيشترين ميانخين نمره مربوط به حيطه ايثار در حرفه برستارى و كمترين مربوط به حيطه ابقا در ثرستارى بود (جدول شماره r). همجنين از بين ابعاد عدالت سازمانى كمترين ميانخين مربوط به عدالت توزيعى و بيشترين مربوط به عدالت تعاملى بود (جدول

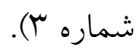

شركت كندكان در يُزوهش اطمينان داده شد كه تمام

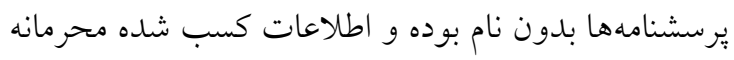

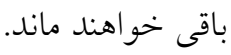

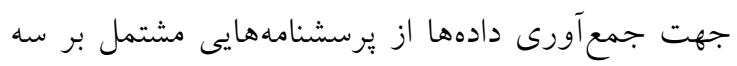
بخش استفاده شد. بخش اول، يرسشنامه اطلاعات جمعيت شناختى شامل سن، جنسيت، وضعيت تأهل، ميزان تحصيلات، سمت، محل كار، نوبت كار، سابقه كار و وضعيت استخدام بود. بخش دوم مربوط به يرسشنامه تعهل حرفهاى برستاران بود.

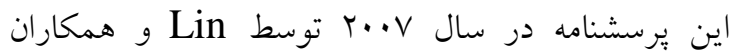

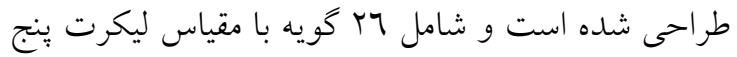

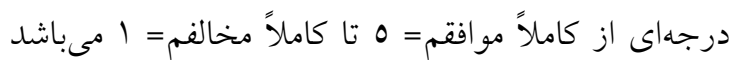

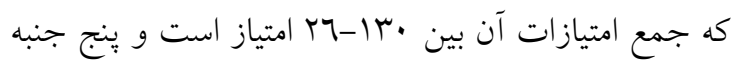

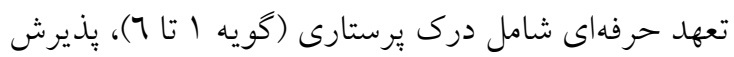
يرستارى (كويه V تا • (1)، تعامل كاركنان يُرستارى (كويه

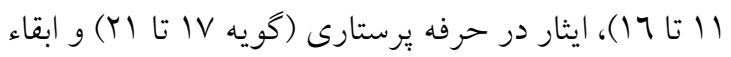

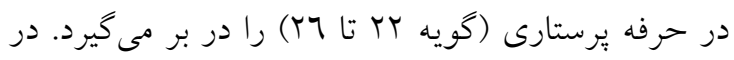

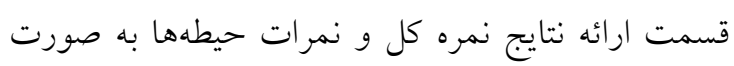

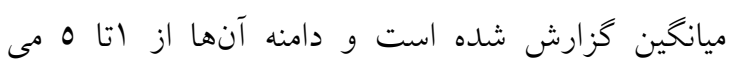
باشد (rT) بخش سوم مربوط به يرسشنامه عدالت سازمانى بود. اين

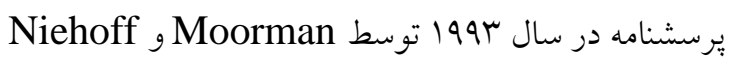

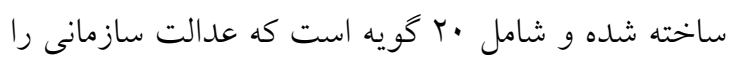

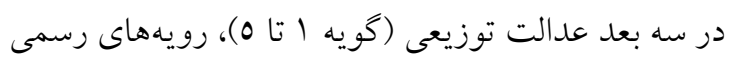

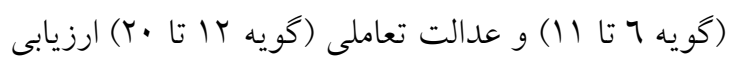
مى كند. نمرهذذارى اين يرسشنامه بر اساس مقياس ليكرت

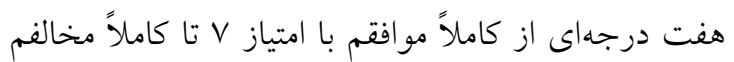

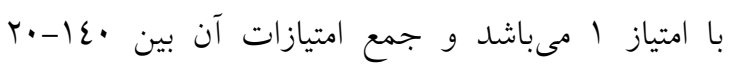
مىباشد. در قسمت ارائه نتايج نمره كل و نمرات حيطهها

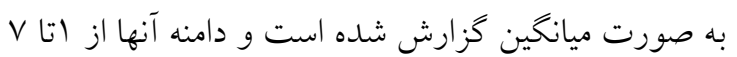


جدول شماره (: اطلاعات جمعيت شناختى برستار ان شهر زاهدان

\begin{tabular}{|c|c|c|c|}
\hline | ل مرصد & فراوانى & \multicolumn{2}{|c|}{ اطلاعات جمعيت شناختى } \\
\hline$\wedge \cdot 10$ & $r \varepsilon$. & 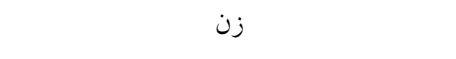 & جنسيت \\
\hline 19/0 & $\Delta \wedge$ & مرد & \\
\hline$r q / 9$ & 119 & مجرد & \\
\hline $7 \cdot / 1$ & iva & متأهل & وضعيت تاهل \\
\hline 90 & rur & 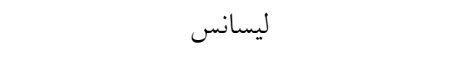 & سطح تحصيلات \\
\hline$\circ$ & 10 & فوق ليسانس & \\
\hline $71 / V$ & $1 \wedge \varepsilon$ & تخصصى و فوق تخصصى امام على (ع) & \\
\hline$r \mid / 1$ & $\pi$ & تخصصى خاتم الانبياء (ص) & \\
\hline $0 / \varepsilon$ & 17 & تخصصى بوعلى & بيمارستان محل خدمت \\
\hline$r / \varepsilon$ & $1 \cdot$ & تخصصى اطفال على اصغر (ع) & \\
\hline$\varepsilon / V$ & $1 \varepsilon$ & روانيزشكى بهاران & \\
\hline$r / V$ & 11 & جشم يز شكى الزهرا (س) & \\
\hline $97 / 7$ & YM & 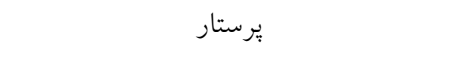 & 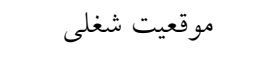 \\
\hline$r / \varepsilon$ & $1 \cdot$ & 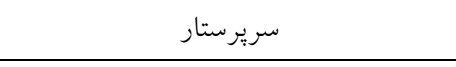 & \\
\hline$r \varepsilon / 0$ & $1 . r$ & رسمى & \\
\hline$r \varepsilon / r$ & vr & 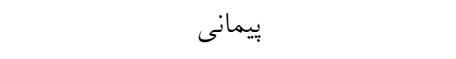 & وضعيت استخدام \\
\hline$r Y / 0$ & $7 \varepsilon$ & 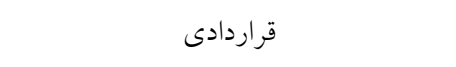 & \\
\hline $19 / 1$ & 09 & 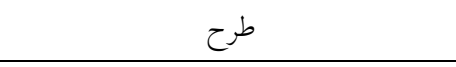 & \\
\hline$v \varepsilon / 0$ & rrr & 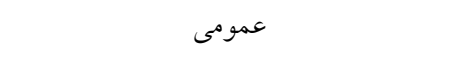 & بخش كارى \\
\hline$r o / 0$ & v7 & ويزه & \\
\hline $\mid r / \varepsilon$ & $r v$ & ثابت & نوبت كارى \\
\hline$\wedge V / \nearrow$ & r71 & دركردش & \\
\hline
\end{tabular}

جدول شماره r: ميانكين و انحر اف معيار تعهد حرفه اى و ابعاد آن

\begin{tabular}{|c|c|c|c|c|c|c|}
\hline ابقا در حرفه & ايثار در حرفه & تعامل كاركنان & يذيرش & درى & تعهد حرفهاى & متغير \\
\hline ير برستارى & يرستارى & ير بتارى & بر ستارى & يرستارى & & \\
\hline
\end{tabular}

انحراف معيار ميانكين

جدول شماره ب: ميانكين و انحراف معيار عدالت سازمانى و ابعاد آن

\begin{tabular}{|c|c|c|c|c|}
\hline عدالت تعاملى & رويههاى رسمى & عدالت توزيعى & عدالت سازمانى & متغير \\
\hline$\varepsilon / 10 \pm 1 / v q$ & $\varepsilon / .9 \pm 1 / V r$ & $r / 29 \pm 1 / 01$ & $r / q V \pm 1 / 0 r$ & انحر اف معيار \ـميانكين \\
\hline
\end{tabular}

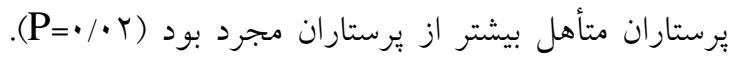

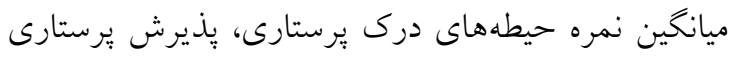

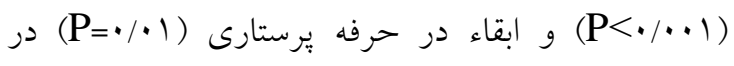

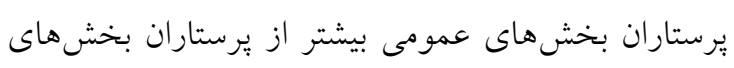

$$
\text { ويزه بود (جدول شماره ع). }
$$

مقايسه ميانخين نمرات تعهد حرفهاى و ابعاد آن برحسب اطلاعات جمعيت شناختى نشان داد كه ميانخين حيطه هاى درى يرستارى (1)

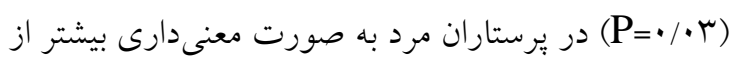

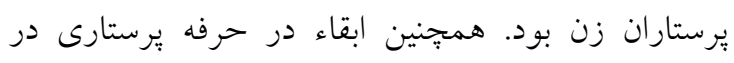


جدول شماره §: ميانكَين و انحراف معيار تعهد حرفهاى و ابعاد آن برحسب اطلاعات جمعيت شناختى

\begin{tabular}{|c|c|c|c|c|c|c|c|c|}
\hline ابقا در حرفه & ايثار در حرفه & تعامل كار كنان & يذ يذ يرش & درك برستارى & تعهد حرفهاى & تعداد & \multicolumn{2}{|c|}{$\begin{array}{c}\text { اطلاعات جمعيت } \\
\text { شناختى }\end{array}$} \\
\hline 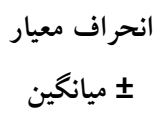 & 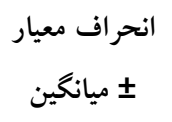 & 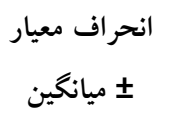 & $\begin{array}{c}\text { I انحر اف معيار } \\
\text { Iيانخين }\end{array}$ & 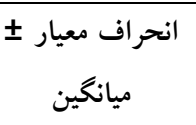 & $\begin{array}{c}\text { انحر اف معيار } \\
\text { ميانخين. }\end{array}$ & & & \\
\hline$r / T \cdot \pm \cdot / V \varepsilon$ & $\varepsilon / 1 r \pm \cdot / V \varepsilon$ & $r / 97 \pm \cdot / 7 V$ & $r / N T \pm \cdot / \wedge r$ & $r / r r \pm \cdot / V V$ & $\mathrm{r} / 77 \pm \cdot / 0 \mathrm{~V}$ & $r \varepsilon$. & زن & \\
\hline$r / \% q \pm \cdot / 07$ & $\varepsilon / \cdot\urcorner \pm \cdot / v \wedge$ & $r / A V \pm \cdot / N V$ & $r / \Lambda \cdot \pm \cdot / V \Lambda$ & $r / 71 \pm \cdot / V r$ & r/VO $\pm \cdot / 0 T$ & $\Delta \Lambda$ & مرد & جنسيت \\
\hline$\cdot / \cdot r$ & $\cdot 10 \mathrm{~V}$ & $\cdot / \varepsilon$ & .100 & $\cdot 1 \cdot 1$ & $\cdot / \mu$ & & $\mathbf{P}^{*}$ & \\
\hline$r / / r \pm \cdot / N r$ & $\varepsilon / 10 \pm \cdot / N r$ & $r / \varepsilon \cdot \pm \cdot / \eta \Lambda$ & $\Gamma / \Lambda \cdot \pm \cdot / \Lambda r$ & $r \mu \cdot \pm \cdot / \Lambda \mu$ & $r / 77 \pm \cdot / 0 \mathrm{~V}$ & 119 & مجرد & \\
\hline & $\varepsilon / 1 \cdot \pm \cdot / \vee\urcorner$ & $r / q 1 \pm \cdot / v \cdot$ & $r / v \cdot \pm \cdot / \Lambda 1$ & $r / \varepsilon r \pm \cdot / V r$ & $r / 79 \pm \cdot / 07$ & 189 & متأهل & وضعيت \\
\hline$\cdot / \cdot r$ & .100 & ו ו & Tr/r & $\cdot / \varepsilon$ & $\cdot / 79$ & & $\mathbf{P}^{*}$ & تأهل \\
\hline$r / Y V \pm \cdot / V I$ & $\varepsilon / \cdot\urcorner \pm \cdot / / \wedge$ & $r / 91 \pm \cdot / V r$ & $r / T V \pm \cdot / A r$ & $r / \varepsilon \cdot \pm \cdot / V \varepsilon$ & $r / 77 \pm \cdot / 07$ & $1 \cdot r$ & رسمى & \\
\hline$r / Y\urcorner \pm \cdot / V\urcorner$ & $\varepsilon / / r \pm \cdot / A r$ & $r / q V \pm \cdot / 7 \varepsilon$ & $r / N \varepsilon \pm \cdot N r$ & r/To $\pm \cdot / \Lambda T$ & $r / 79 \pm \cdot / 00$ & VT & بيمانى & وضعيت \\
\hline$r / \mid V \pm \cdot / 7 l$ & $\varepsilon / / \varepsilon \pm \cdot / \neg \Lambda$ & $r / 90 \pm \cdot / V V$ & $r / \Lambda \cdot \pm \cdot / \Lambda 7$ & $r / r q \pm \cdot / v 1$ & $r / 7 \Lambda \pm \cdot / 0 \Lambda$ & $7 \varepsilon$ & قراردادى & استخدام \\
\hline$r / Y \mu \pm \cdot / V O$ & $\varepsilon / 1 \wedge \pm \cdot / 7 q$ & $r / 9 \Lambda \pm \cdot / 71$ & $r / v q \pm \cdot / \wedge q$ & $r / r V \pm \cdot / V q$ & $r / v \cdot \pm \cdot / 07$ & 09 & طرح & \\
\hline$\cdot / \wedge \varepsilon$ & $\cdot|\wedge|$ &.$/ 91$ & $\cdot / \sqrt{ } \varepsilon$ &.$/ 91$ & $\cdot / 91$ & & $\mathbf{P}^{* \text { *涼 }}$ & \\
\hline$r / \mu 1 \pm \cdot / 77$ & $\varepsilon / 17 \pm \cdot N r$ & $r / 90 \pm \cdot / 7 \Lambda$ & $r / \Lambda 7 \pm \cdot / V \Lambda$ & $r / 01 \pm \cdot / 79$ & r/VO $\pm \cdot / 0 r$ & TYY & عمومى & بخش \\
\hline$r / r \pm \pm \cdot / \wedge$. & $r / 9 \Lambda \pm \cdot / / q$ & $r / q r \pm \cdot / V r$ & $r / \mu q \pm \cdot / \Lambda \varepsilon$ & $\mathrm{r} / \cdot \cdot \pm \cdot / \wedge \mathrm{V}$ & $r / \varepsilon V \pm \cdot / 7)$ & $v 7$ & ويزه & كارى \\
\hline$\cdot 1 \cdot 1$ & $.1 \cdot 7$ & •/Ar & $<\bullet / \cdots+1$ & $<\cdot / \cdot+1$ & $<\bullet / \bullet \cdot$ & & $\mathbf{P}^{*}$ & \\
\hline$r / Y 1 \pm \cdot / \tau \varepsilon$ & $\varepsilon / 1 \cdot \pm \cdot / 7 q$ & $r / 97 \pm \cdot / N V$ & r/VE $\pm \cdot / V_{0}$ & $r / \Gamma V \pm \cdot / V \mu$ & $r / 70 \pm \cdot / 0 r$ & rv & ثابت & نوبت \\
\hline$r / T \varepsilon \pm \cdot / V Y$ & $\varepsilon / 11 \pm \cdot$ /No & $r / 9 \varepsilon \pm \cdot / 7 \Lambda$ & $r / v \varepsilon \pm \cdot / \wedge r$ & $r / \varepsilon \cdot \pm \cdot / V \Lambda$ & $r / 7 \Lambda \pm \cdot / 07$ & ז7| & درگردش & كارى \\
\hline$\cdot / A$. &.$/ 91$ &.$/ 9$. &.$/ 91$ & & $\cdot / V r$ & & $\mathbf{P}^{*}$ & \\
\hline
\end{tabular}

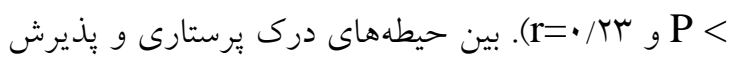

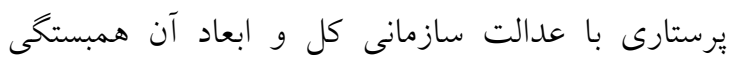

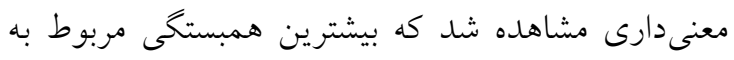

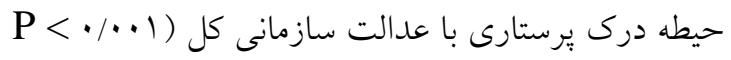

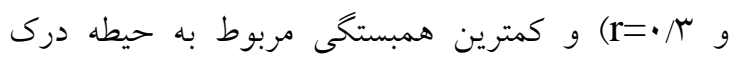

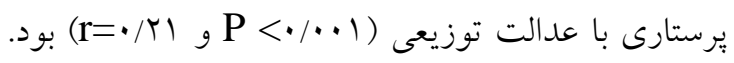

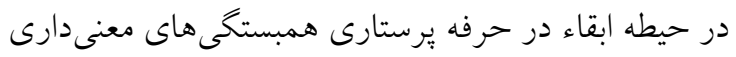
با عدالت سازمانى كل (r P

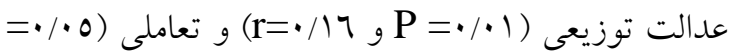
و P دارى مشاهده نشد (P>•/ P (جدول شماره 7).
ميانخين نمره عدالت سازمانى كل و ابعاد عدالت توزيعى و

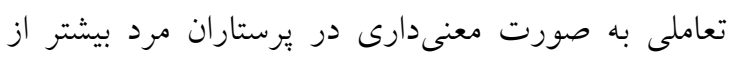

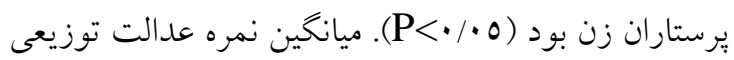
به صورت معنى دارى در يرستاران بخشهاى عمومى بيشتر

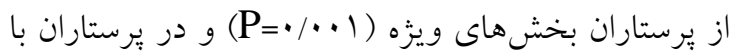
نوبت كارى ثابت بيشتر از يرستاران با نوبت كارى در كردش

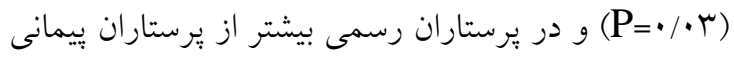

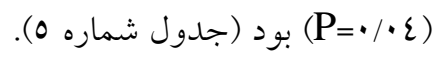
نتيجه ضريب همبستكى وييرسون بين دو متغير عدالت

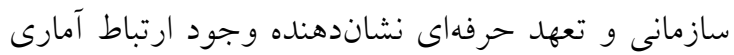
مثبت معنى دارى بين اين دو متغير در يرستاران بود ( ( .. • . 
جدول شماره ه: ميانكين و انحراف معيار عدالت سازمانى و ابعاد آن برحسب اطلاعات جمعيت شناختى

\begin{tabular}{|c|c|c|c|c|c|c|}
\hline عدالت تعاملى & رويههاى رسمى & عدالت توزيعى & عدالت سازمانى & تعداد & \multirow{2}{*}{\multicolumn{2}{|c|}{ اطلاعات جمعيت }} \\
\hline انحراف معيار 土 ميانخين & انحر اف معيار 土 ميانخين & انحر اف معيار 土 ميانخين & انحراف معيار 土 ميانخين & & & \\
\hline$\{/ \cdot 0 \pm 1 / \wedge 1$ & $\varepsilon \pm 1 / V T$ & . & $r / \Lambda 7 \pm 1 / 0$. & $r \varepsilon$. & زن ان & \\
\hline$\varepsilon / 0 V \pm 1 / 7 V$ & $\varepsilon / \varepsilon \wedge \pm 1 / N r$ & $\varepsilon / .0 \pm 1 / \wedge$. & $\varepsilon / \varepsilon r \pm 1 / 0 r$ & $0 \wedge$ & مرد & جنسيت \\
\hline$\cdot / \cdot \varepsilon$ & $.1 \cdot 7$ & $\cdot / \cdot 1$ & $\cdot / \cdot 1$ & & $\mathbf{P}^{*}$ & \\
\hline$\varepsilon / \cdot \wedge \pm 1 / \wedge \vee$ & $r / 90 \pm 1 / V \varepsilon$ & $r / 0 r \pm 1 / 7 r$ & $r / 9 \cdot \pm 1 / 7$. & 119 & مجرد & وضعيت \\
\hline$\varepsilon / 19 \pm 1 / V \varepsilon$ & $\varepsilon / 19 \pm 1 / V r$ & $r / \varepsilon \wedge \pm 1 / 00$ & $\varepsilon / \cdot 1 \pm 1 / \varepsilon\rceil$ & 189 & متأهل & تأهل \\
\hline$\cdot / 71$ & $\cdot / Y \varepsilon$ & • & $\cdot / 0 \varepsilon$ & & $\mathbf{P}^{*}$ & \\
\hline$\varepsilon / T V \pm 1 / \wedge r$ & $\varepsilon / 11 \pm 1 / V \varepsilon$ & $r / N T \pm 1 / 09$ & $\varepsilon / \cdot \wedge \pm 1 / 0 r$ & $1 . r$ & رسمى & \\
\hline$r / \wedge 9 \pm 1 / v$. & $r / 90 \pm 1 / N r$ & $r / \bullet \wedge \pm 1 / \varepsilon \varepsilon$ & $r / v 1 \pm 1 / 20$ & VT & بيمانى & \\
\hline$\varepsilon / .7 \pm 1 / 17$ & $\varepsilon / 17 \pm 1 / V \wedge$ & $r / V V \pm 1 / 7 \Lambda$ & $\varepsilon / \cdot r \pm 1 / \tau r$ & $7 \varepsilon$ & قراردادى & وضعيت \\
\hline$\varepsilon / N O \pm 1 / N 7$ & $\varepsilon / 1 \wedge \pm 1 / 79$ & $r / T q \pm 1 / 01$ & $\varepsilon / \cdot r \pm 1 / \varepsilon V$ & 09 & طرح & استخدام \\
\hline$\cdot / \varepsilon r$ & $\cdot / 17$ & $\cdot / \cdot r$ & $\cdot|\varepsilon|$ & & $\mathbf{P}^{* * *}$ & \\
\hline$\varepsilon / Y\urcorner \pm 1 / N\urcorner$ & $\varepsilon / 1 \Lambda \pm 1 / N r$ & $r / 77 \pm 1 / 01$ & $\varepsilon / .9 \pm 1 / 0$. & TrY & عمومى & بخش \\
\hline$r / \Lambda \mu \pm 1 / \Lambda \varepsilon$ & $r / \Lambda \varepsilon \pm 1 / V \varepsilon$ & $r / 99 \pm 1 / 2 V$ & $r / 7 r \pm 1 / 0 r$ & V7 & ويزه & كارى \\
\hline$\cdot / \cdot V$ & $\cdot / \varepsilon$ & $\cdot / \cdot 1$ & $\cdot / \cdot r$ & & $\mathbf{P}^{*}$ & \\
\hline$\varepsilon / O V \pm 1 / A r$ & $\varepsilon / \pi 7 \pm 1 / 90$ & $\varepsilon / \cdot r \pm \mid / \Lambda 1$ & $\varepsilon / \Gamma V \pm 1 / V T$ & rv & ثابت & \\
\hline$\varepsilon / .9 \pm 1 / N \Lambda$ & $\varepsilon / \cdot 7 \pm 1 / \mathrm{V}$. & $r / \varepsilon r \pm 1 / 0 \varepsilon$ & $r / 91 \pm 1 / \varepsilon \wedge$ & |Yा & درخردش & نوبت كارى \\
\hline $1 / Y V$ & r & $\cdot / \cdot r$ &.$/ .9$ & & $\mathbf{P}^{*}$ & \\
\hline
\end{tabular}

جدول شماره 7: همبستكى تعهد حرفهاى و ابعاد آن با عدالت سازمانى و ابعاد آن

\begin{tabular}{|c|c|c|c|c|c|}
\hline \multicolumn{4}{|c|}{ عدالت سازمانى } & \multicolumn{2}{|l|}{ متغير } \\
\hline عدالت تعاملى & رويههاى رسمى & عدالت توزيعى & كل & & \\
\hline $\mathrm{r}=\cdot / \pi$. & $\mathrm{r}=\cdot / \mathrm{r}$. & $\mathrm{r}=\cdot / \pi \mathrm{I}$ & $\mathrm{r}=\cdot / r^{\mu}$ & كل & \\
\hline $\mathrm{p}<\cdot / \cdot \cdot 1$ & $\mathrm{p}<\cdot / \cdot \cdot 1$ & $\mathrm{p}<\bullet / \cdot \cdot 1$ & $\mathrm{p}<\cdot / \cdot \cdot 1$ & & \\
\hline $\mathrm{r}=\cdot / \Gamma \wedge$ & $\mathrm{r}=\cdot / \Gamma \wedge$ & $\mathrm{r}=\cdot / \pi$ & $\mathrm{r}=\cdot / r$ & درك يرستارى & \\
\hline $\mathrm{p}<\cdot / \cdot \cdot 1$ & $\mathrm{p}<\cdot / \cdot \cdot 1$ & $\mathrm{p}<\cdot / \cdot \cdot 1$ & $\mathrm{p}<\cdot / \cdot \cdot 1$ & & تعهد \\
\hline $\mathrm{r}=\cdot / r \varepsilon$ & $\mathrm{r}=\cdot / \pi r$ & $\mathrm{r}=\cdot / T V$ & $\mathrm{r}=\cdot / T \wedge$ & يذّيرش برستارى & 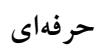 \\
\hline $\mathrm{p}<\bullet / \cdot \cdot 1$ & $\mathrm{p}<\cdot / \cdot \cdot 1$ & $\mathrm{p}<\bullet / \cdot \cdot 1$ & $\mathrm{p}<\bullet / \cdot \cdot 1$ & & \\
\hline$r=0 / .0$ & $r=\bullet / \bullet \wedge$ & $r=0 / .7$ & $\mathrm{r}=\cdot / \cdot \mathrm{V}$ & تعامل كاركنان يِرستارى & \\
\hline $\mathrm{p}=\cdot / \pi 7$ & $\mathrm{p}=\cdot / 17$ & $\mathrm{p}=\cdot / \kappa \wedge$ & $\mathrm{p}=\cdot / r)$ & & \\
\hline $\mathrm{r}=\cdot / .7$ & $\mathrm{r}=\cdot / \cdot \wedge$ & $\mathrm{r}=.1 .9$ & $\mathrm{r}=\cdot \cdot / \wedge$ & ايثار در حرفه برستارى & \\
\hline $\mathrm{p}=\cdot / \mu 1$ & $\mathrm{p}=\cdot / 19$ & $\mathrm{p}=\cdot / 1$ & $\mathrm{p}=\cdot / 17$ & & \\
\hline $\mathrm{r}=\cdot / 11$ & $\mathrm{r}=\cdot / \cdot \mathrm{V}$ & $r=\cdot / 17$ & $\mathrm{r}=\cdot / \mu r$ & ابقاء در حرفه بِرستارى & \\
\hline $\mathrm{p}=\cdot / \cdot 0$ & $\mathrm{p}=\cdot / \wedge \Lambda$ & $\mathrm{p}=\cdot / \cdot \cdot 1$ & $p=\cdot / \cdot r$ & & \\
\hline
\end{tabular}


بود. در اين زمينه نتيجه ئزوهش حاضر با نتايج ئزوهش

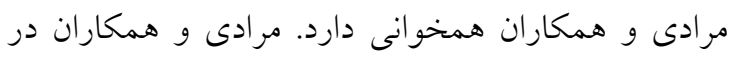

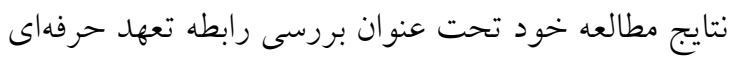
و رضايت شغلى برستاران شاغل در بيمارستانهاى دولتى -

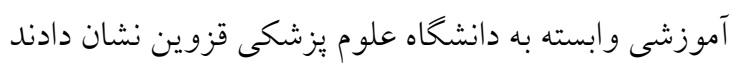

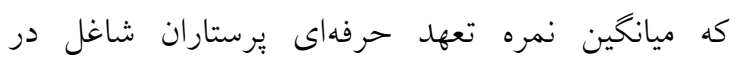
Aيمارستانهاى قزوين در حد متوسط مىباشد (IV). Hamdan

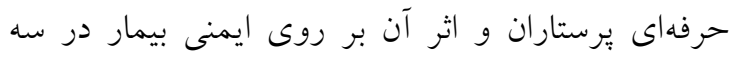
بيمارستان آموزشى، خصوصى و دولتى در اردن انجام دادند كه نتايج مطالعه حاكى از تعهد حرفهاى متوسط يرستاران

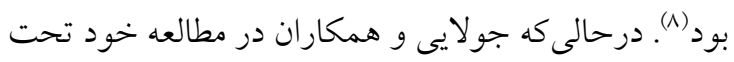
عنوان بررسى ارتباط وقوع خطاهاى دارويى و تعهد

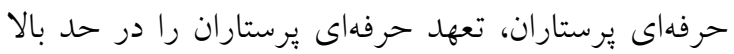

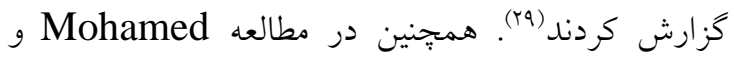

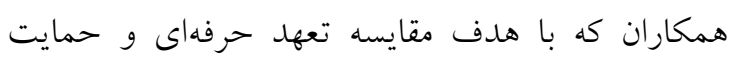

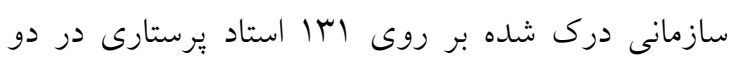

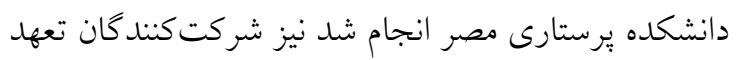

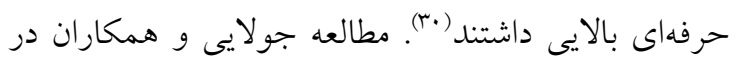

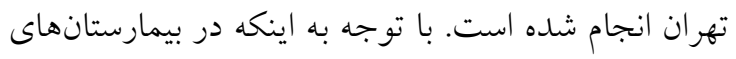

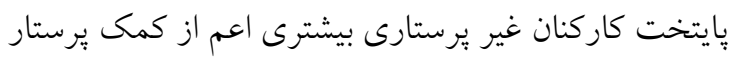

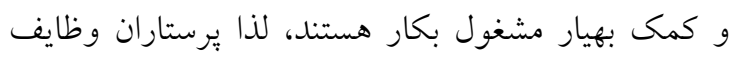
حرفه اى خود را مى توانند بهتر و بيشتر انجام دهند و انجام اين وظايف تخصصى منجر به رضايت و در نتيجه تعهد

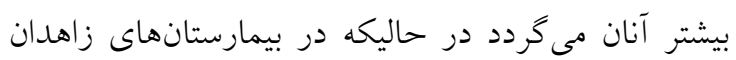

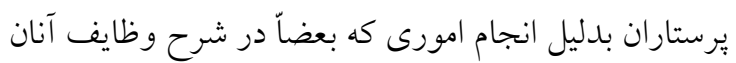

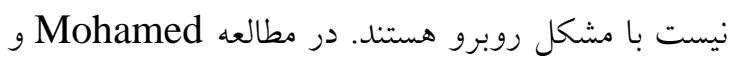

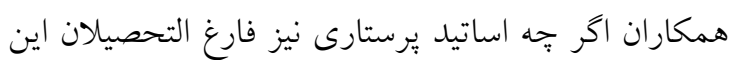
رشته هستند اما شايد قادر به لمس مسائل و مشكلات خاص كاركنان يرستارى شاغل در بيمارستان نباشند.

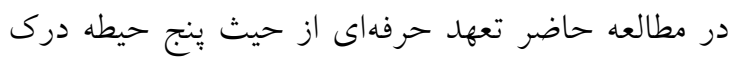
برستارى، يذيرش بِرستارى، تعامل كاركنان بِرستارى، ايثار

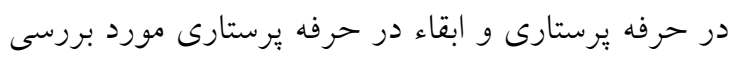
قرار كرفت. از ميان حيطههاى تعهل حرفهاى بيشترين

\section{بحث و نتيجهكيرى}

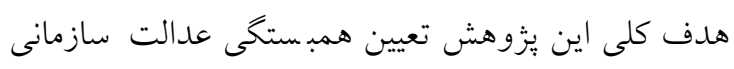

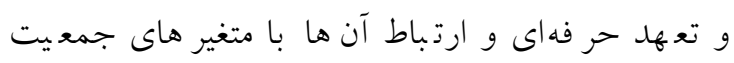

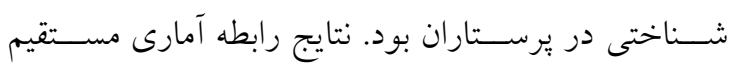

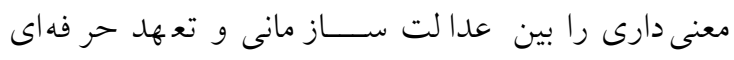

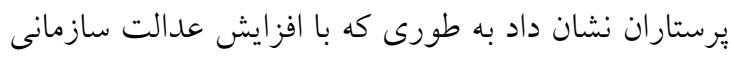

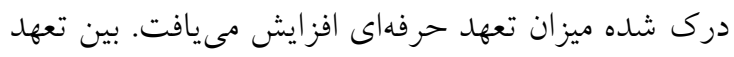
حر فهاى كل و حيطه هاى درك برسـتارى و يذيرش

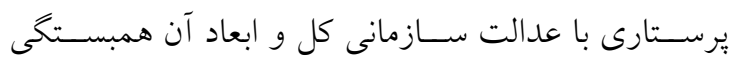
معنى دارى مـ شاهده شد، اما بين حيطه هاى تعامل كاركنان

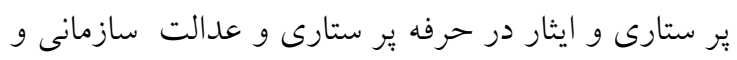
ابعاد آن همبستكى معنى دارى مشاهده نشد. در حيطه ابقاء

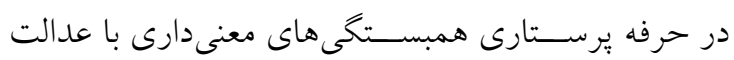

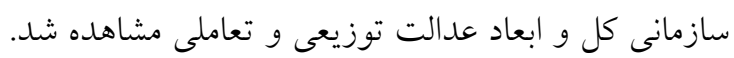

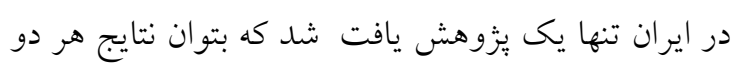

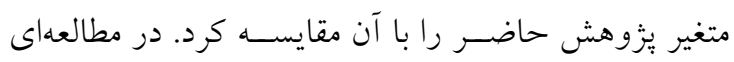
مقطعى كه توســط اكبرى و همكارانش در بيرجند انجام

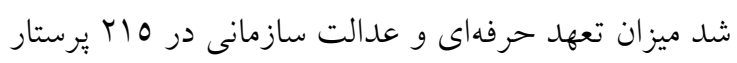
شـاغل در دو بيمارستان مورد بررسى قرار كرفت. نتايج

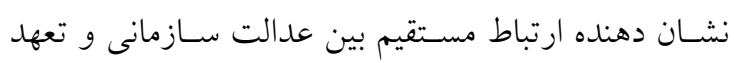
حرفهاى وجود داشت. بين تعهد حرفهاى كل و ابعاد آن با دهان

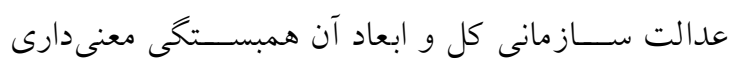

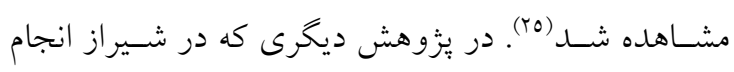

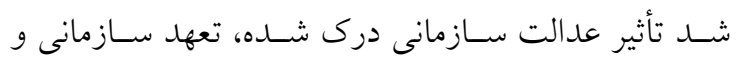

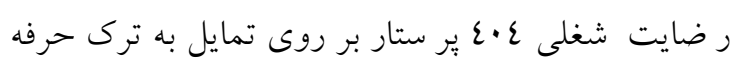

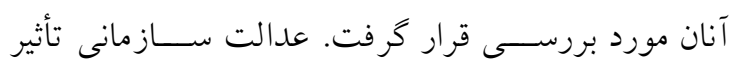

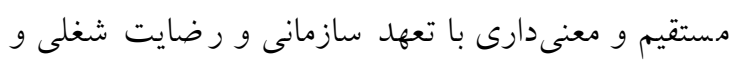

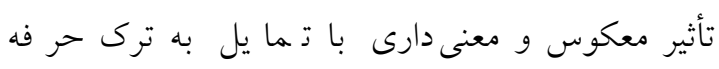

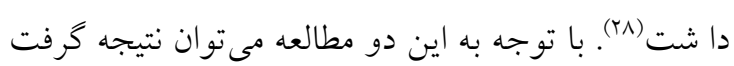

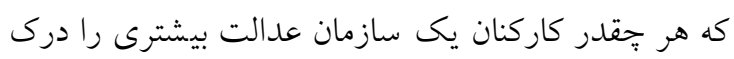

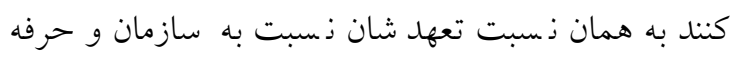
بيشتر مىشود و تمايل كمترى نسبت به ترى حرفه دارند.

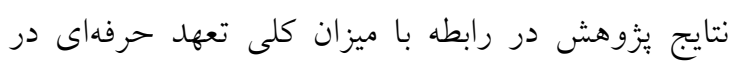

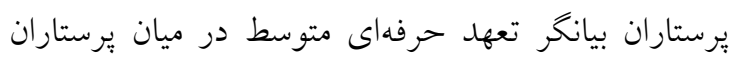


سازمانى يرستاران بيمارستانهاى اصفهان در سطح متوسط

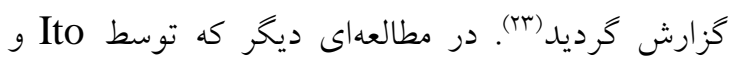

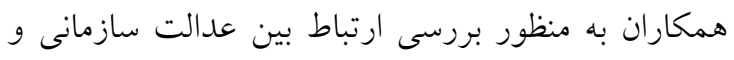

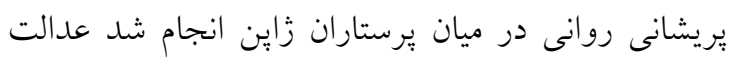

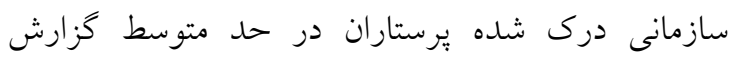

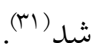
از بين سه بعد عدالت سازمانى بيشترين ميانخين نمره عدالت سازمانى مربوط به حيطه عدالت تعاملى و كمترين مربوط به حيطه عدالت توزيعى بود. اين يافتهها با نتايج مطالعات حاتم و همكاران، اكبرى و همكاران و جوادى و

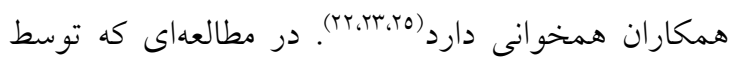
و همكاران در ميان يرستاران زاين انجام شد كمترين

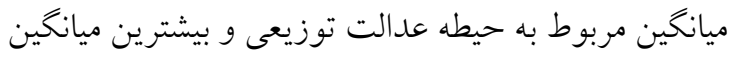

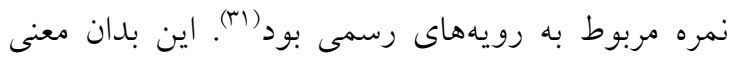

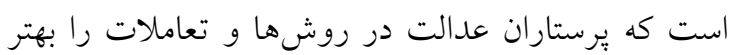

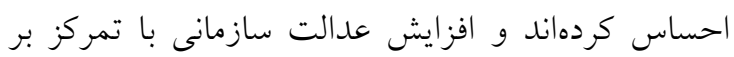

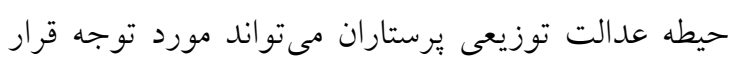
كيرد. برستاران به عنوان يكى از اعضاى اصلى تيم ارائه خدمات

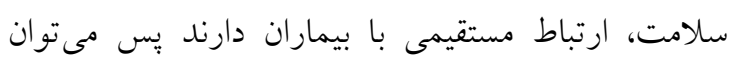
انتظار داشت هر مداخلهاى براى افزايش تعهد حرفهاى آن ها در نهايت سبب بهبود كيفيت خدمات يرستارى كردد. بنابراين با توجه به همبستخى مثبى كه در مطالعه حاضر

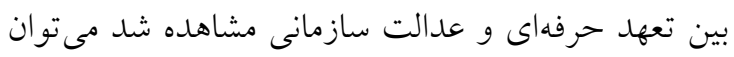
با برنامه ريزى مداخلاتى جهت افزايش عدالت سازمانى درك شده يرستاران به خصوص بعد عدالت توزيعى، باعث

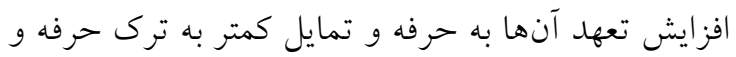
ارتقاء خدمات يرستارى شد. به عنوان مثال مىتوان عدالت توزيعى را از طريق مداخلاتى همجيون اصلاح نظام يرداخت حقوق و مزايا، تخصيص عادلانه مسئوليتها و استخدام نيروهاى كمك يرستار و كمك بهيار افزايش داد.

تعارض منافع: هيج گَونه تعارض منافع از سوى نو يسند كان بيان نشده است.
ميانخين نمره تعهد حرفهاى يرستاران مربوط به حيطه ايثار در حرفه يرستارى و كمترين مربوط به حيطه ابقاء در يرستارى بود. در مطالعه اكبرى و همكاران نيز بيشترين ميانخين نمره تعهلد حرفهاى يرستاران مربوط به حيطه ايثار

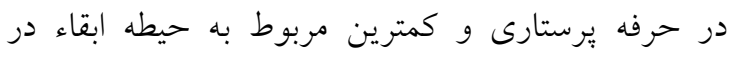

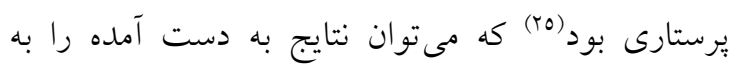

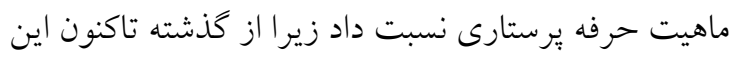
حرفه با سلامت و جان انسانها در ارتباط بوده است و و

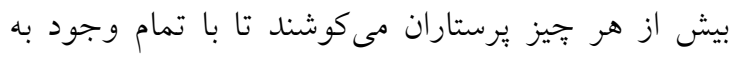

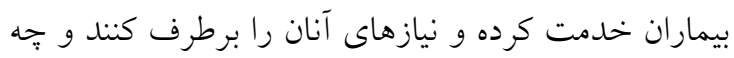
بسا تحقق اين هدف نيازمند ايثار بيشتر كاركنان مىباشد.

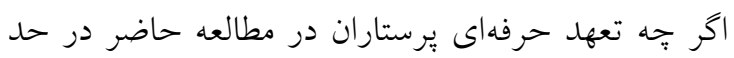

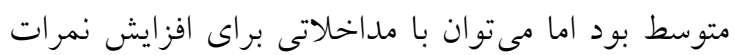

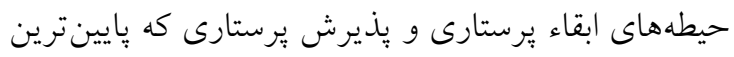
نمرات را داشتند تعهد حرفهاى يرستاران را افزايش داد.

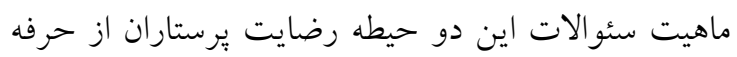

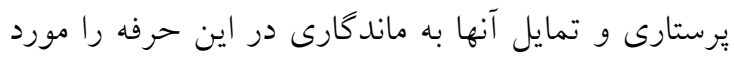

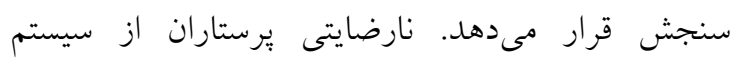

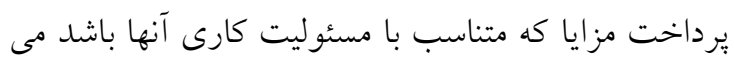

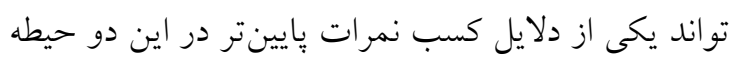
باشد. در مطالعه حاضر ميانخين نمره عدالت سازمانى درى شده

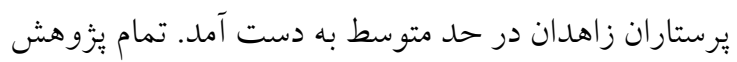

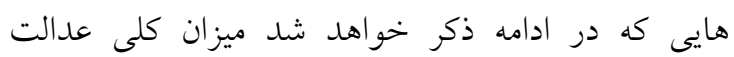

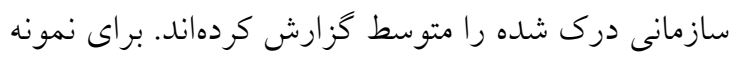

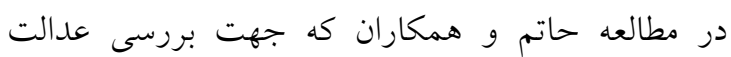
سازمانى درى شده يرستاران شيراز انجام شد نيز ميانخين

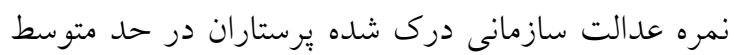
كزارش شد (Yr). اكبرى و همكاران نيز در مطالعه خود كه به منظور بررسى ارتباط عدالت سازمانى و تعهد حرفهاى

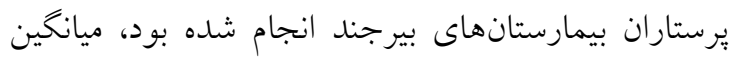

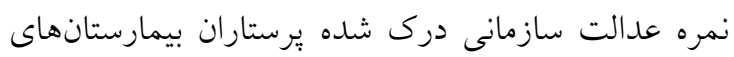

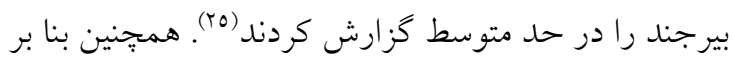
نتايج مطالعه جوادى و همكاران ميانخين نمره عدالت 


$$
\begin{aligned}
& \text { خاتمالانبياء (ص)، بوعلى، تخصصى اطفال على اصغر، }
\end{aligned}
$$

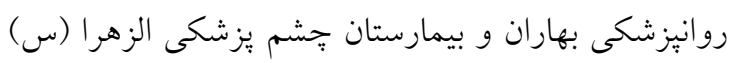

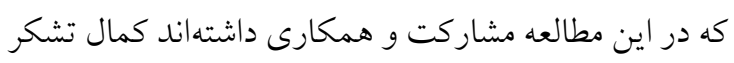

$$
\begin{aligned}
& \text { و قدردانى را داريم. }
\end{aligned}
$$

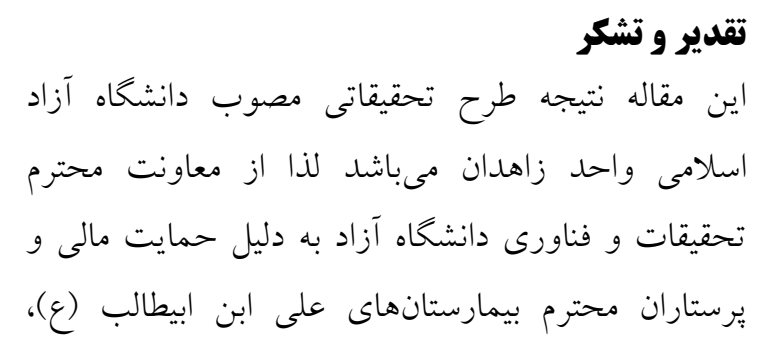

\section{References}

1. Jafaragaee F, Parvizy S, Mehrdad N, Rafii F. Concept analysis of professional commitment in Iranian nurses. Iranian journal of nursing and midwifery research. 2012;17(7):472-9. [Persian]

2. Lu K-Y, Chang L-C, Wu H-L. Relationships between professional commitment, job satisfaction, and work stress in public health nurses in Taiwan. J Prof Nurs. 2007;23(2):110-6.

3. Teng CI, Dai YT, Shyu YIL, Wong MK, Chu TL, Tsai YH. Professional commitment, patient safety, and patient-perceived care quality. J Nurs Scholarsh. 2009;41(3):301-9.

4. Honyenuga B, Adzoyi P. Professional commitment of nurses in Ghana: The case of the Volta region. APJRBM. 2012;3(1):12-27.

5. Teng C-I, Shyu Y-IL, Chang H-Y. Moderating effects of professional commitment on hospital nurses in Taiwan. J Prof Nurs. 2007;23(1):47-54.

6. Jafaraghaee F, Ebadi A, Negarandeh R, Mehrdad N. A professional commitment scale for clinical nurses: A study protoco. Medical journal of the Islamic Republic of Iran. 2017;31:123. [Persian]

7. Shali M, Joolaee S, Hooshmand A, Haghani H, Masoumi H. The relationship between incidence of patient falls and nurses' professional commitment. Journal of hayat. 2016;22(1):27-37. [Persian]

8. Al-Hamdan Z, Dalky H, Al-Ramadneh J. Nurses' professional commitment and its effect on patient safety. Global journal of health science. 2018;10(1):111-9.

9. Akram M, Malik MI, Sarwar M, Anwer M, Ahmad F. Relationship of teacher competence with professional commitment and job satisfaction at secondary level. The AYER. 2015;4:58-70.

10. Barać I, Prlić N, Plužarić J, Farčić N, Kovačević S. The Mediating Role of Nurses'professional Commitment in the Relationship between Core Self-Evaluation and Job Satisfaction. Int J Occup Med environ Health. 2018;31(5):649.

11. Duarte MB. Organisational and professional commitments: The influence in nurses' organisational citizenship behaviours. Tékhne. 2015;13(1):2-11.

12. Donkor N, Andrews L. Ethics, culture and nursing practice in Ghana. Int Nurs Rev. 2011;58(1):109-14.

13. Mrayyan MT, Al-Faouri I, editors. Career commitment and job performance of Jordanian nurses. Nursing forum; 2008;43(1):24-37.

14. Gould D, Fontenla M. Commitment to nursing: results of a qualitative interview study. Journal of Nursing Management. 2006;14(3):213-21.

15. Nogueras DJ. Occupational commitment, education, and experience as a predictor of intent to leave the nursing profession. Nursing economics. 2006;24(2):86-93.

16. Jafaraghaee F, Mehrdad N, Parvizy S. Influencing factors on professional commitment in Iranian nurses: A qualitative study. Iranian journal of nursing and midwifery research. 2014;19(3):3018. [Persian]

17. Moradi M, Khatooni M, Zeighami R, Sheikhi M. Relationship between Professional Commitment and Job Satisfaction in Qazvin's Pubic Educational Hospital Nurses. Medical Ethics Journal. 2013;7(24):55-78. [Persian]

18. Imran R, Allil K. The impact of organizational justice on employee retention: evidence from Oman. International Review of Management and Marketing. 2016;6(2):246-9.

19. Leow KL, Khong KW. Organizational commitment: The study of organizational justice and leader-member exchange (LMX) among auditors in Malaysia. Int J Bus Inf. 2009;4(2):162-98. 
20. Sjahruddin H, Sudiro A. Organizational justice, organizational commitment and trust in manager as predictor of organizational citizenship behavior. Interdiciplinary $J$ of contemporary Res Bus(IJCRB). 2013;4(12):133-41.

21. Zarifi F, Yoosefi B, Sadeghi Borojerdi S. The Relationship Between Organizational Justice And Job Involvement In Employees Of Physical Education Organization Of Islamic Republic Of Iran. Journal Of Sport Management. 2013;4(15):157-74. [Persian]

22. Hatam N, Fardid M, Kavosi Z. Perceptions of organizational justice among nurses working in university hospitals of shiraz: a comparison between general and specialty settings. Nursing and midwifery studies. 2013;2(4):77-82.

23. Javadi M, Karimi S, Raiesi A, Yaghoubi M, Shams A, Kadkhodaie M. Organizational justice and responsiveness in selected private and public hospitals of Isfahan, Iran. Journal of School of Public Health and Institute of Public Health Research. 2012;9(4):11-20. [Persian]

24. Mortazavi S, Kargozar N. Study of the relationship between organizational justice, job satisfaction, and affective commitment on customer oriented behavior of nurses of Imam Reza hospital, Mashhad, Iran. Journal of Zanjan University of Medical Sciences. 2012;20(80):84-97. [Persian]

25. Akbari O, Vagharseyyedin SA. The Relationship of Organizational Justice with Nurses'professional Commitment. Modern Care Journal (Scientific Quarterly Of Birjand Nursing \& Midwifery Faculty). 2015;12(1):31-8. [Persian]

26. Lin C-J, Wang H-C, Li T-C, Huang L-C. Reliability and Validity of Nurses. Mid-Taiwan Journal of Medicine. 2007;12(2):65-75.

27. Niehoff BP, Moorman RH. Justice as a mediator of the relationship between methods of monitoring and organizational citizenship behavior. Academy of Management journal. 1993;36(3):527-56.

28. Fardid M, Hatam N, Kavosi Z. A path analysis of the effects of nurses' perceived organizational justice, organizational commitment, and job satisfaction on their turnover intention. Nurs Midwifery Stud. 2018;7(4):157-62.

29. Jolaee S, Shali M, Haghani H. The relationship between incidence of medication errors and nurse's professional commitment. Medical Ethics Journal. 2014;8(28):101-19. [Persian]

30. Mohamed LK, EL-Shaer AM. Professional commitment and perceived organizational support among nursing academic staff: a comparative study. Med J Cairo Univ. 2013;81(2).

31. Ito Y, Nakamura S, Kimura R, Mori M, Okanoya J, Somemura H, et al. Relationship between organizational justice and psychological distress among hospital nurses. Kitasato Medical Journal. 2015;45(1):38-44. 